\title{
Studying the reproductive skipping behavior in long-lived birds by adding nest inspection to individual-based data
}

Article in Ecological Applications · March 2011

DOI: 10.1890/09-2339.1 · Source: PubMed

CITATIONS

26
READS

41

7 authors, including:

Ana Sanz-Aguilar

Mediterranean Institute for Advanced St...

40 PUBLICATIONS 346 CITATIONS

SEE PROFILE

Meritxell Genovart

Spanish National Research Council

75 PUBLICATIONS 1,030 CITATIONS

SEE PROFILE

\section{Giacomo Tavecchia}

Mediterranean Institute for Advanced St...

92 PUBLICATIONS 1,820 CITATIONS

SEE PROFILE

\section{Daniel Oro}

Mediterranean Institute for Advanced St... 252 PUBLICATIONS 5,939 CITATIONS

SEE PROFILE 


\title{
Studying the reproductive skipping behavior in long-lived birds by adding nest inspection to individual-based data
}

\author{
Ana Sanz-Aguilar, ${ }^{1,2,4}$ Giacomo Tavecchia, ${ }^{1}$ Meritxell Genovart, ${ }^{1}$ Jose Manuel Igual, ${ }^{1}$ Daniel Oro, ${ }^{1}$ \\ Lauriane Rouan, ${ }^{3}$ and Roger Pradel ${ }^{2}$ \\ ${ }^{1}$ Population Ecology Group, Instituto Mediterráneo de Estudios Avanzados, IMEDEA (CSIC-UIB), \\ Miquel Marqués 21,07190 Esporles, Mallorca, Spain \\ ${ }^{2}$ Biometry and Population Biology Group, Centre d'Ecologie Fonctionelle et Evolutive (CEFE-CNRS), \\ UMR 51751919 Route de Mende, Montpellier F-34293 France \\ ${ }^{3}$ Biological Systems Department UPR104 (CIRAD-BIOS), Adaptation Agroecologique et Innovation Variétale Office (AIVA), \\ Avenue Agropolis Lavalette TA A 104/01 Montpellier 34398 France
}

\begin{abstract}
The frequency at which individuals breed is an important parameter in population, as well as in evolutionary, studies. However, when nonbreeding individuals are absent from the study area, the reproductive skipping is usually confounded with a recapture failure and cannot be estimated directly. Yet, there are situations in which external information may help to estimate reproductive skipping. Such a situation is found with nest-tenacious birds: the fact that an individual is not encountered in its previous nest is a good indication that it must be skipping reproduction. We illustrate here a general probabilistic framework in which we merged the classical individual capture-recapture information with nest-based information to obtain the simultaneous estimate of recapture, survival, reproductive skipping, and within-colony breeding dispersal probabilities using multi-event models. We applied this approach to Cory's Shearwater (Calonectris diomedea), a long-lived burrow-nesting seabird. By comparing results with those obtained from the analysis of the capture-recapture information alone, we showed that the model separates successfully the probabilities of recapture from those of temporal emigration. We found that the probabilities of future reproduction and breeding-site fidelity were lower for individuals temporarily absent from the colony, suggesting a lower intrinsic quality of intermittent breeders. The new probabilistic framework presented here allowed us to refine the estimates of demographic parameters by simply adding nest-based data, a type of information usually collected in the field but never included in the analysis of individual-based data. Our approach also provides a new and flexible way to test hypotheses on temporal emigration and breeding dispersal in longitudinal data.
\end{abstract}

Key words: breeding dispersal; breeding frequency; Calonectris diomedea; capture-recapture; Cory's Shearwater; individual-based data; multi-event; recapture; reproductive trade-offs.

\section{INTRODUCTION}

The Cormack-Jolly-Seber capture-recapture model is useful for estimating survival probability from presence/ absence of individually marked animals, and the model is built on the assumption that all emigration from the studied area is permanent (Lebreton et al. 1992). The existence of temporary emigration among individuals in the population may cause biased estimates of the parameters obtained by classical capture-recapture models (Kendall and Nichols 1995, 2002, Fujiwara and Caswell 2002), but also can reflect biological processes such as reproductive skipping, also called

Manuscript received 17 December 2009; revised 16 April 2010; accepted 10 May 2010. Corresponding editor: T. R. Simons.

${ }^{4}$ Present address: Biometry and Population Biology Group, Centre d'Ecologie Fonctionelle et Evolutive (CEFE-CNRS), UMR 51751919 Route de Mende, Montpellier F-34293 France. E-mail: ana.sanzaguilar@cefe.cnrs.fr intermittent breeding or sabbatical (Kendall et al. 2009). In particular, in the presence of temporary emigration, the recapture probability can be viewed as a combination of the true recapture probability (i.e., probability of capturing an individual given that it is alive and present in the study area, which is usually a function of recapture effort), and the probability of presence (i.e., the probability that an individual that is alive is present in the study area, which is biologically more meaningful [Kendall and Nichols 1995, Viallefont et al. 1995]). Several approaches have been developed for dealing with special cases of this general problem, which include a particular experimental design or specific model constraints. Kendall and Nichols (1995) and Kendall et al. (1997), for example, developed an approach based on Pollock's robust design, in which multiple recaptures within a given sampling occasion provide unbiased estimates of parameters in the presence of temporary emigration. Fujiwara and Caswell (2002) developed stage-structured models that included nonobservable 
stages representing individuals that emigrate temporally. A similar multistate approach was used by Crespin et al. (2006) and Jenouvrier et al. (2008), who considered temporary emigrants to move to a nonobservable state and to share parameters with individuals in observable states, a condition previously tested by Cam et al. (1998) to study the evolutionary consequences of intermittent breeding in the Black-legged Kittiwake (Rissa tridactyla). Kendall and Nichols (2002), Schaub et al. (2004), and Kendall et al. (2009) found that models allowing estimation of relevant parameters in the presence of an unobservable state required either extra information (e.g., secondary capture occasions, dead recoveries, incidental observations), or, alternatively, specific model or parameter constraints: reducing the order of Markovian transition probabilities, imposing a degree of determinism on transition probabilities, removing state specificity of survival probabilities, or imposing temporal constancy of parameters.

In many monitoring programs of animal populations, individuals are not observable during part of their life history cycle (Bailey et al. 2004). The estimation of temporary emigration is of special interest to measure dispersal, disturbance, proportion breeding, and population size (Kendall et al. 1997, Bried and Jouventin 1999, Bailey et al. 2004). However, the most common use of temporary emigration models involves situations in which only breeding individuals are observable. The absence from their breeding colony of individuals known to be alive and known to have bred in earlier years (i.e., intermittent breeding or sabbatical) has been documented in birds (Warham 1990), mammals (Schwarz and Stobo 1997), and reptiles (Kendall and Bjorkland 2001). Nevertheless, the quantification of such phenomena has remained a challenge for a long time despite its importance in population dynamics, conservation biology, management, and evolutionary studies (Bradley et al. 2000, Bailey et al. 2004, Jenouvrier et al. 2005). The intermittent breeding behavior can represent an extreme case of bet-hedging strategy where reproduction is influenced by an individual decision related to its future chances to reproduce and/or survive under particular environmental conditions (Stearns 1992, Chastel et al. 1995, Jenouvrier et al. 2005). Theoretically, according to the prudent-parent hypothesis, individuals that skip reproduction may avoid potential costs of reproduction, and they should have a higher future breeding probability at the next occasion than do actual breeders (Drent and Daan 1980, Le Bohec et al. 2007). Nevertheless, several studies have shown that intermittent breeders are typically lowquality individuals with lower probabilities of future reproduction and/or survival (Cam et al. 1998, Barbraud and Weimerskirch 2005). On the other hand, temporary emigration can be a consequence of a constraint due to competition with conspecifics for breeding sites, death of the former mate, or divorce (Harris and Wanless 1995, Catry et al. 1998, Bruinzeel 2007). After skipping one breeding season, chances of returning to the old nest with the old partner are probably lower, which may result in higher rates of change of nest or a second sabbatical (Cam et al. 1998, Danchin and Cam 2002, Bruinzeel 2007). In order to distinguish between the alternative explanations of skipping behavior, one needs to be able to estimate not only the probability of skipping but also the probabilities of returning to the colony and of reoccupying the same breeding site after a sabbatical period; to this aim, nest-tenacious birds may be a good biological model.

Colonial seabirds, particularly procellariiforms, are known to be highly site- and mate-tenacious (Warham 1990), but intra-colony movements between nests and divorce have been documented in several species (Thibault 1994, Mougin et al. 2000, Bried et al. 2003). As a procellariiform, Cory's Shearwater (Calonectris diomedea) exhibits strong fidelity to the pair and to the nest site (i.e., a burrow), and both members of the pair have similar investment in reproduction (Thibault 1994, Mougin et al. 1997, Igual et al. 2007). Individuals skipping reproduction are sometimes present in their old burrows, but in most cases are not observable due to their absence from the colony (Jenouvrier et al. 2008). Monitoring programs concerning this species and others with similar breeding habits are usually based on individual capture-recapture data and burrow-based information, e.g., breeding success or occupation (Oro et al. 2004, Sanz-Aguilar et al. 2008, Igual et al. 2009). Nevertheless, burrow-based information is seldom used for estimating survival or breeding propensity using capture-recapture models and is traditionally used only to estimate breeding success.

Here we illustrate a multi-event probabilistic framework (Pradel 2005) that allows the combining of individual capture-recapture data and nest-based data (i.e., monitoring or inspection of burrow, burrow occupancy, and identity of the individuals occupying each burrow), collected in a breeding colony of Cory's Shearwater. Our aims were (1) to estimate simultaneously the probability of recapture, survival, reproductive skipping, and burrow dispersal; (2) to compare estimates of survival and recapture probabilities obtained by the multi-event approach with those obtained by the classic unistate capture-recapture modeling; and (3) to test the effects of burrow fidelity and skipping reproduction on the future probabilities of burrow dispersal and skipping reproduction again. An advantage of this approach is that it does not require imposing more or less arbitrary parameter constraints, nor an increased level of disturbance with secondary capture occasions (but see also Kendall et al. 2009). This example is directly applicable to many other bird species such as seabirds, anseriforms, ciconiforms, raptors, woodpeckers, or passeriforms, provided that individuals exhibit some degree of breeding-site tenacity (Newton 1989, Warham 1990, Cézilly et al. 2000, Blums et al. 2002). Moreover, the present approach can be adapted 
to other species such as reptiles or amphibians for which a breeding habitat can be identified.

\section{Methods}

\section{Study area and population monitoring}

The data used here were collected each year from 2001 to 2008 on a medium-sized breeding colony of Cory's Shearwater $(\sim 200$ pairs $)$ at the small island of Pantaleu (2.5 ha, $26 \mathrm{~m}$ a.s.1.) in the Balearic Archipelago, Spain $\left(39^{\circ} 34^{\prime} \mathrm{N}, 2^{\circ} 21^{\prime} \mathrm{E}\right)$. Individuals are present at the breeding colony from the beginning of March to the end of October (Genovart 2001) and breed in burrows, mainly located under boulders or vegetation. Most burrows (185) are accessible and were tagged and visited during the incubation and chick-rearing period to record laying dates, burrow occupancy, and breeding success. In occupied burrows, once per breeding season, breeding adults were captured and marked (if not marked yet) with stainless steel rings with a unique alphanumeric code to allow identification of individuals. The manipulation of the individuals was never a cause of nest desertion. Because some nest tags can be lost due to, for example, winter rock falls, the probability of finding and inspecting a nest was less than one.

\section{Model design}

The capture of a marked individual at the burrow that it occupied in the previous year is the result of a series of probabilities: the probability that the individual is alive, that it breeds, that it is faithful to its burrow, that the burrow is inspected by the observer, and, ultimately, that the individual is captured. By contrast, when an individual is not captured, it may be breeding in its nest and have escaped capture, it may be skipping reproduction (i.e., be in sabbatical), it may have moved to a new nest site, or it may have died. Each of these four outcomes can be treated as a different state of the individual. In the case of non-recaptured birds, the additional information on the burrow occupancy will help to estimate the probability associated with each possible situation, i.e., individual state. With this additional information, the capture history of each individual incorporates observable events at the individual level (i.e., presence in its previous burrow or in a new different burrow), as well as at the nest level (e.g., occupied/not occupied). Pradel (2005) developed a general model for stratified capture-recapture histories that allows the inclusion of parameters for latent (i.e., not observable) processes. This so-called multi-event model (Pradel 2005) relates the true state of the individual with the observed event through a series of conditional probabilities. It is a generalization of the classical capture-recapture models that can be viewed as the simplest probabilistic framework for relating the captured/not-captured event with the dead/alive state. In order to compare estimates on recapture and survival probabilities obtained by the classical unistate approach (i.e., using individual capture-recapture data alone) and by the novel multi-event approach that incorporates burrow information, we performed unistate and multievent modeling with the same data set.

Goodness of fit.-The goodness of fit (GOF) of the unistate model, assuming a full-time variation of recapture and survival parameters (the Cormack-JollySeber model, CJS; Lebreton et al. 1992) was assessed using program U-CARE 2.2.2 (Choquet et al. 2009a). The program includes a specific test for the presence of transient birds, i.e., birds seen only at marking, that compares whether the survival probability soon after marking differs from subsequent survival probabilities (denoted Test 3.SR). This effect can be accommodated by including specific parameters for the first survival after marking (Pradel et al. 1997). It also includes a specific test for trap dependence (denoted Test 2.CT) that verifies whether recapture probability depends on the past history of the individuals (Pradel 1993). The trap-dependence effect can be corrected by recoding capture histories and including an additional parameter for subsequent recaptures (Pradel 1993). Additional lack of fit can be taken into account by scaling model deviances using a scale parameter, classically denoted $\hat{c}$, calculated as the goodness-of-fit statistic on its degree of freedom (Lebreton et al. 1992). At this moment, specific goodness-of-fit tests for multi-event models are not available. Consequently, we incorporated the effects observed when examining the goodness of fit of the CJS model to our multi-event models and scaled model deviances by $\hat{c}$. Note, however, that in the multi-event models developed here, the trap-dependence effect is structurally included, as these models incorporate temporary emigration

Unistate approach.-Capture-recapture data were organized in individual capture histories (see Lebreton et al. 1992). For each capture-recapture occasion, $t$, we considered two events, captured (denoted " 1 ") and not captured (denoted "0"). As it was done previously (Igual et al. 2009), no information about burrow occupancy or burrow identity was included. Recapture and survival probabilities were modeled as a function of time and of those effects found by the GOF tests (i.e., transient and trap dependence; see Results). Models were built and fitted to the data using program M-SURGE 1.8.1 (Choquet et al. 2004). Model selection was based on Akaike's Information Criterion adjusted for small sample size $\left(\mathrm{AIC}_{\mathrm{c}}\right)$ and overdispersion $(\mathrm{Q})$ calculated as

$$
\mathrm{QAIC}_{\mathrm{c}}=\frac{\mathrm{Rdev}}{\hat{c}}+2 \mathrm{np}
$$

where Rdev represents the relative model deviance; $\hat{c}$ is the variance inflation factor; and $n p$ is the number of separately identifiable parameters in the model (Burnham and Anderson 2002). Additionally for each model $j$, we calculated the Akaike weights, $w_{j}$, as an index of its relative plausibility (Burnham and Anderson 2002). The structure retained for survival was then used to 


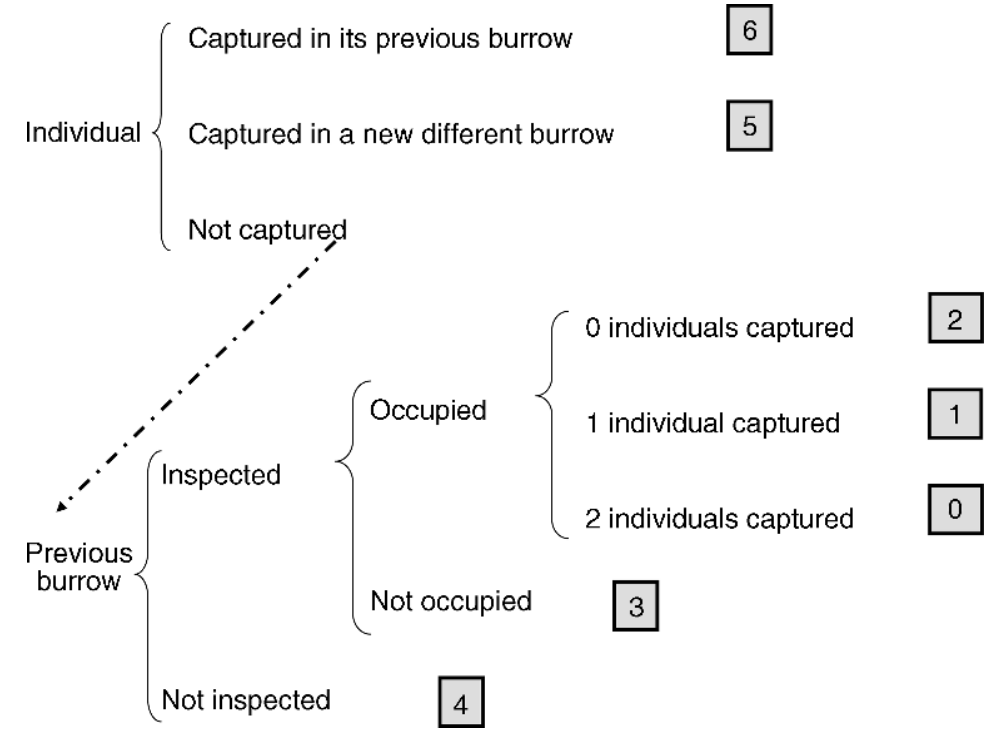

FIG. 1. Multi-event event codes in capture-recapture (numbers within squares) integrating individual- and burrow-based information for Cory's Shearwaters (Calonectris diomedea). The two events considered in the unistate model, 0 (not captured) and 1 (captured), correspond to the 0-4 and 5-6 events, respectively, in the multi-event model. Where the individual is not recaptured, if its last known burrow is occupied, (0) indicates two occupants are captured, (1) indicates one occupant is captured, and (2) indicates no occupant is captured; (3) indicates its last known burrow is found unoccupied; (4) indicates its last known burrow is not inspected. Where the individual is captured or recaptured breeding, (5) indicates it is in a new different burrow; and (6) indicates it is in its previous burrow.

simplify model selection in multi-event models, given that survival parameters are equivalent in both approaches.

Multi-event approach.-Multi-event models were built using program E-SURGE 1.4.4 (Choquet et al. 2009b). This program distinguishes three basic types of parameters: the initial state probabilities, the transition probabilities, and the event probabilities (Pradel 2005, Choquet et al. 2009b). Models included four biological states: AP, individual alive and breeding in the same burrow as in the previous year; AN, individual alive and breeding in a new different burrow; AS, individual alive and in sabbatical (i.e., not breeding at the colony); and $\mathrm{D}$, individual dead. The last two states are not observable. The initial state in our models was arbitrarily decided to be always AP because we cannot know if an individual bred in a different burrow before its first capture and only breeders are captured (see the specific matrix design in the Appendix). In each capturerecapture occasion, $t$, we considered seven possible events, noted from 0 to 6 (Fig. 1): (6) the breeding individual is captured for the first time or recaptured breeding in its previous known burrow; (5) the individual is recaptured breeding in a new different burrow; (4) the individual is not recaptured at occasion $t$ and its last known burrow has not been inspected; (3) the individual is not recaptured and its last known burrow is found empty; (2) the individual is not recaptured and its last known burrow is found occupied, but no occupant is captured; (1) the individual is not recaptured, but its last known burrow is found occupied and one occupant is captured; (0) the individual is not recaptured, but its last known burrow is found occupied and the two occupants are captured. The two events considered in the unistate model, " 0 " and " 1 ," correspond to the $0-4$ and 5-6 events, respectively, in the multi-event model.

Transitions between states were modeled in a two-step approach (see the specific matrix design in the Appendix). Firstly, we used the structure of survival probability retained in the unistate approach. Subsequently, we modeled the between-state transitions conditional on bird survival (i.e., the probability of sabbatical and the probability of changing burrow). In order to simplify our model approach, we did not considered the potential effects of time on between-state transitions probabilities and we considered three different structures reflecting a priori biological hypothesis (Fig. 2):

$H_{1}$ ) Future change of burrow and breeding probabilities are related to previous individual decisions and/or constraints.

$\mathrm{H}_{2}$ ) Change of burrow is a random event among breeders and a constraint for individuals that skipped reproduction. This also assumes that the future probability of breeding is related to previous investment in reproduction or to individual quality, i.e., differs between breeders and birds skipping reproduction.

$\mathrm{H}_{3}$ ) Burrow dispersal and skipping reproduction are random events (i.e., they are not related to previous individual fidelity to the nest site or to skipping reproduction behavior).

The structure for the seven events was modeled in a stepwise procedure (Fig. 3; see the specific matrix design 
in the Appendix). First we modeled individual recapture probabilities, denoted $R$ (step 1), and then, for the individuals not encountered in the colony, we used information from the previous known burrow that was occupied by the individual. We modeled, successively, the probability of burrow inspection, $I$ (step 2), probability of burrow occupancy, $K$ (step 3 ), probability of capture of the first occupant in the last known burrow of a not-encountered individual, $F$ (step 4), and probability of capture of the second occupant in the last known burrow of an not-encountered individual, $S$ (step 5). As in the previous analysis, model selection was based on model AIC values.

\section{Results}

\section{Unistate model}

In the unistate analysis, the overall test of goodness of fit of the CJS model was statistically significant $\left(\chi^{2}\right.$ $=106.52$, $\mathrm{df}=23, P=0.006$; Table 1 ) because newly marked birds had a lower apparent survival than birds already marked $\left(\chi^{2}=20.15, \mathrm{df}=6, P=0.003\right.$; Table 1$)$, and the recapture probability was modified following a capture event $\left(\chi^{2}=70.12, \mathrm{df}=5, P<0.001\right.$; Table 1$)$. To appropriately account for transience and trap dependence in our data, we modified our first model to include an effect of age in survival (transient effect) and trap dependence in recapture probabilities $\left(\chi^{2}=16.25\right.$, $\mathrm{df}=$ $12, P=0.18$; Table 1 ). Remaining heterogeneity was accounted for by scaling model deviances using a variance inflation factor, $\hat{c}=1.35$ (Table 1 ).

We modeled the probability of recapture by testing an additive effect of time on trap-dependence groups (Table 2). We then modeled survival probability as a function of time, age after marking (i.e., the "transient" effect), and their statistical interaction. The model with the highest Akaike weight (Table 2, model 5; w $=0.75$ ) assumed a parallel variation in recapture probabilities between birds recaught immediately and not recaught immediately over the study period (Fig. 4) and a constant survival probability of both newly marked and resident individuals. Estimates of survival for newly marked birds and resident birds were 0.77 (95\% CI = $0.70-0.82)$ and $0.87(95 \% \mathrm{CI}=0.82-0.90)$, respectively (Table 2, model 5).

\section{Multi-event model}

For multi-event capture-recapture models, we applied the same $\hat{c}$ as in the unistate approach $(\hat{c}=1.35)$ and modeled survival probabilities including a transient effect. To model between-state transitions (i.e., sabbatical and change of burrow probabilities) and event probabilities, we began model selection by the complex model that considered between-state transitions dependent on departure state $\left(H_{1}\right)$ and time-dependent event probabilities (Table 3, model 1). We simplified this model by considering the probability of burrow inspection (Table 3, model 2) and the probability of burrow occupancy (Table 3, model 3) to be constant
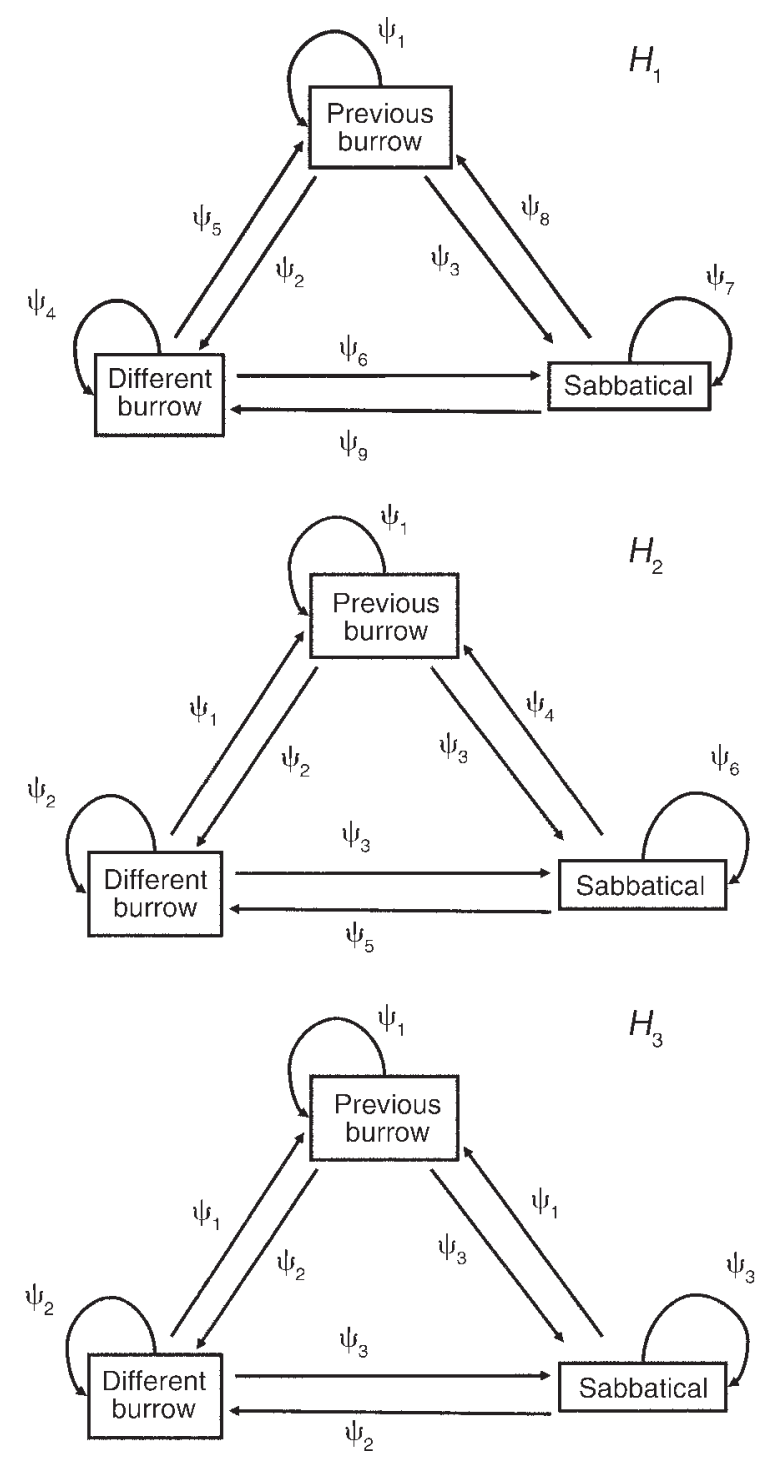

FIG. 2. Between-state transition structures in accordance with the biological hypotheses tested $\left(\mathrm{H}_{1}, \mathrm{H}_{2}\right.$, and $\mathrm{H}_{3}$; see Methods: Model design: Multi-event approach). Transitions sharing the same number were modeled to be equal.

over time. A model in which probabilities of recapture and capture of the occupants of last known burrows of not-encountered individuals $(R, F$, and $S)$ were constant (Table 3, model 4) was not retained in terms of QAIC $_{c}$. Once we selected the structure of event probabilities that minimized $\mathrm{QAIC}_{\mathrm{c}}$, we tested the other two biological hypotheses on between-state transition probabilities (Table 3: $H_{2}$, model 5 and $H_{3}$, model 6). The best model in terms of Akaike's weight was model $5(w=$ 0.78; Table 3), which considered that individuals that bred had different future probabilities of skipping reproduction (i.e., sabbatical) and of changing burrow than individuals who previously were in sabbatical. Model-averaged estimates of transition probabilities indicated that probabilities of future burrow change 


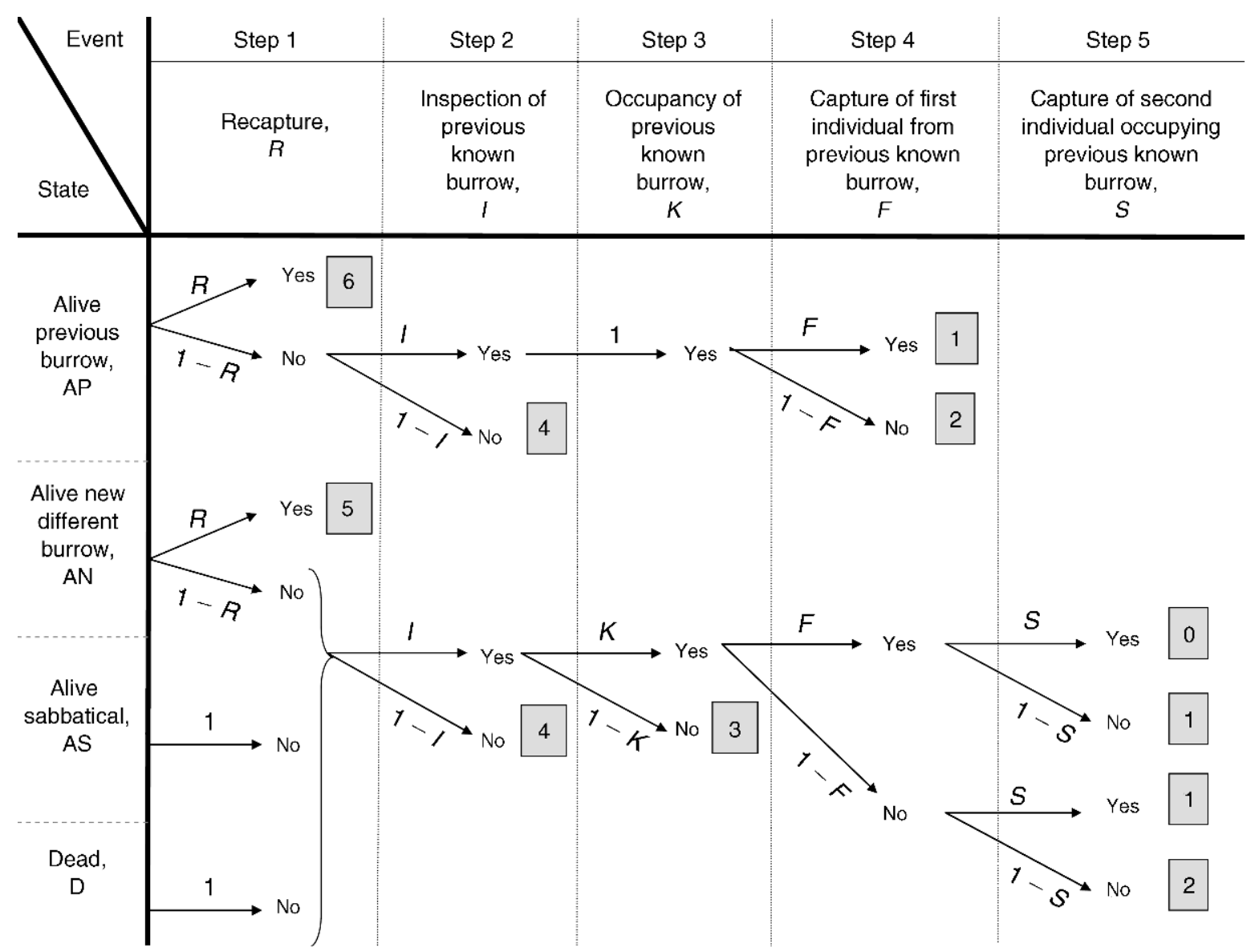

FIG. 3. Modeling the events to study the probability of sabbatical in Cory's Shearwaters, by state. Numbers in gray boxes are the multi-event model capture-recapture codes.

and future sabbatical did not differ between birds that bred in a new burrow and those that bred in the old burrow (Table 4). Model-averaged estimates of survival probabilities of both newly marked and resident birds were very similar to those found in the unistate analysis, $0.78(95 \% \mathrm{CI}=0.71-0.83)$ and $0.87(95 \% \mathrm{CI}=0.82-$ 0.90 ), respectively (Table 3: models $2,3,5$ ). By contrast, the probability of recapture was higher than those values obtained by unistate models, but they showed similar temporal variation (Fig. 4). The probability of burrow inspection was $0.89(95 \% \mathrm{CI}=0.87-0.91)$ and the probability of burrow occupancy was $0.69(95 \% \mathrm{CI}=$ $0.66-0.73)$. The probabilities of capture of the first and of the second occupants of the last known burrow of not-encountered individuals were very similar and lower than recapture probabilities. They showed a similar temporal variation (results not shown).

\section{Discussion}

\section{A new approach to the study of temporary emigration}

Population ecologists use population models to infer future population trajectories or the efficacy of conservation plans. These models typically include estimates of relevant demographic parameters such as survival, breeding propensity, and breeding output whose precision greatly influences the ultimate conclusions and their reliability (Coulson et al. 2001). Estimates of those demographic parameters usually face problems associated with the difficulty of detection of nonbreeding individuals (Cam et al. 1998). When nonbreeders (animals skipping reproduction) are absent from the

TABLE 1. Testing the homogeneity assumptions of the Cormack-Jolly-Seber (CJS) model.

\begin{tabular}{lrrr}
\hline \hline \multicolumn{1}{c}{$\begin{array}{c}\text { Goodness-of-fit } \\
\text { components }\end{array}$} & \multicolumn{1}{c}{$\chi^{2}$} & df & $\hat{c}$ \\
\hline Test 3.SR & $\mathbf{2 0 . 1 5}$ & $\mathbf{6}$ & \\
Test 3.SM & 10.23 & 6 & \\
Test 2.CT & $\mathbf{7 0 . 1 2}$ & $\mathbf{5}$ & \\
Test 2.CL & 6.02 & 6 & \\
CJS model & $\mathbf{1 0 6 . 5 2}$ & $\mathbf{2 3}$ & 4.63 \\
Model with trap dependence & 16.25 & 12 & 1.35 \\
$\quad$ and transients & & & \\
\end{tabular}

Notes: Tests and models are described in Methods: Model design: Goodness of fit; $\hat{c}$ is the goodness-of-fit statistic (variance inflation factor). Significant $\chi^{2}$ statistics $(P<0.05)$ are in boldface. 
TABLE 2. Model statistics for recapture $(P)$ and survival $(\Phi)$ probability of Cory's Shearwaters (Calonectris diomedea) at Pantaleu Island in the Balearic Archipelago, Spain.

\begin{tabular}{|c|c|c|c|c|c|c|c|c|}
\hline \multirow{2}{*}{$\begin{array}{c}\text { Model } \\
\text { no. }\end{array}$} & \multirow[b]{2}{*}{$P$} & \multicolumn{2}{|c|}{$\Phi$} & \multirow[b]{2}{*}{$\mathrm{np}$} & \multirow[b]{2}{*}{ Rdev } & \multirow[b]{2}{*}{ QAIC } & \multirow[b]{2}{*}{$\Delta_{i}$} & \multirow[b]{2}{*}{$w_{i}$} \\
\hline & & $\mathrm{nm}$ & res & & & & & \\
\hline 5 & $\operatorname{trap}+t$ & . & . & 10 & 2178.86 & 1633.97 & 0.00 & 0.75 \\
\hline 6 & trap & . & . & 4 & 2199.96 & 1637.60 & 3.63 & 0.12 \\
\hline 3 & $\operatorname{trap}+t$ & $t$ & . & 16 & 2168.54 & 1638.32 & 4.35 & 0.08 \\
\hline 8 & trap & . & $t$ & 10 & 2186.37 & 1639.53 & 5.56 & 0.05 \\
\hline 4 & trap $+t$ & . & $t$ & 16 & 2171.06 & 1640.19 & 6.22 & 0.03 \\
\hline 7 & trap & $t$ & . & 10 & 2188.72 & 1641.27 & 7.30 & 0.02 \\
\hline 2 & trap & $t$ & $t$ & 16 & 2175.47 & 1643.46 & 9.49 & 0.01 \\
\hline 1 & $\operatorname{trap}+t$ & $t$ & $t$ & 22 & 2160.90 & 1644.67 & 10.69 & 0.00 \\
\hline
\end{tabular}

Notes: Abbreviations are nm, newly marked birds; res, resident birds; np, number of estimable parameters; Rdev: relative deviance; QAIC, Akaike information criterion corrected for overdispersion; $\Delta_{i}$, the QAIC difference between the current model and the one with the lowest QAIC value; $w_{i}$, Akaike's weight. Model notation: $t$, time effect; trap, trap-dependence effect; trap $+t$, parallel variation between recapture of trap-happy and trap-shy birds; "." indicates constant (i.e., no effects considered). The model with the highest $w_{i}$ is in boldface.

study area, their proportion can be directly estimated if the recapture or observation probability of breeders is 1 (Mougin et al. 1997) or when secondary capture occasions are available (Kendall and Nichols 2002). Alternatively, extra information such as dead recoveries, telemetry data, or incidental observations can be used to estimate this parameter (Kendall et al. 2009). In our study, we developed a new modeling approach by including a type of extra information, i.e., the nestbased information, which is normally collected as part of the capture-recapture program itself without additional recapture occasions or effort. This allowed us to simultaneously estimate the probability of temporary emigration (i.e., sabbatical years between reproductions), recapture, and survival without imposing specific model or parameter constraints, as is usually necessary for models including nonobservable states. Moreover, our multi-event approach allowed us to estimate additional parameters such as the probabilities of intra-colonial nest site dispersal, consecutive sabbatical, and changing nest after a sabbatical. Probabilities of burrow inspection and occupancy can be interpreted as a proxy of the monitoring efficiency (Yoccoz et al. 2001) and of the annual available breeding sites. In our case, the probability of burrow inspection was very high and only a small proportion of known burrows was missed. The probabilities of capture of the first and the second occupants in the last known burrow of a not-encountered individual were not biologically meaningful, but their estimation was necessary to estimate with accuracy

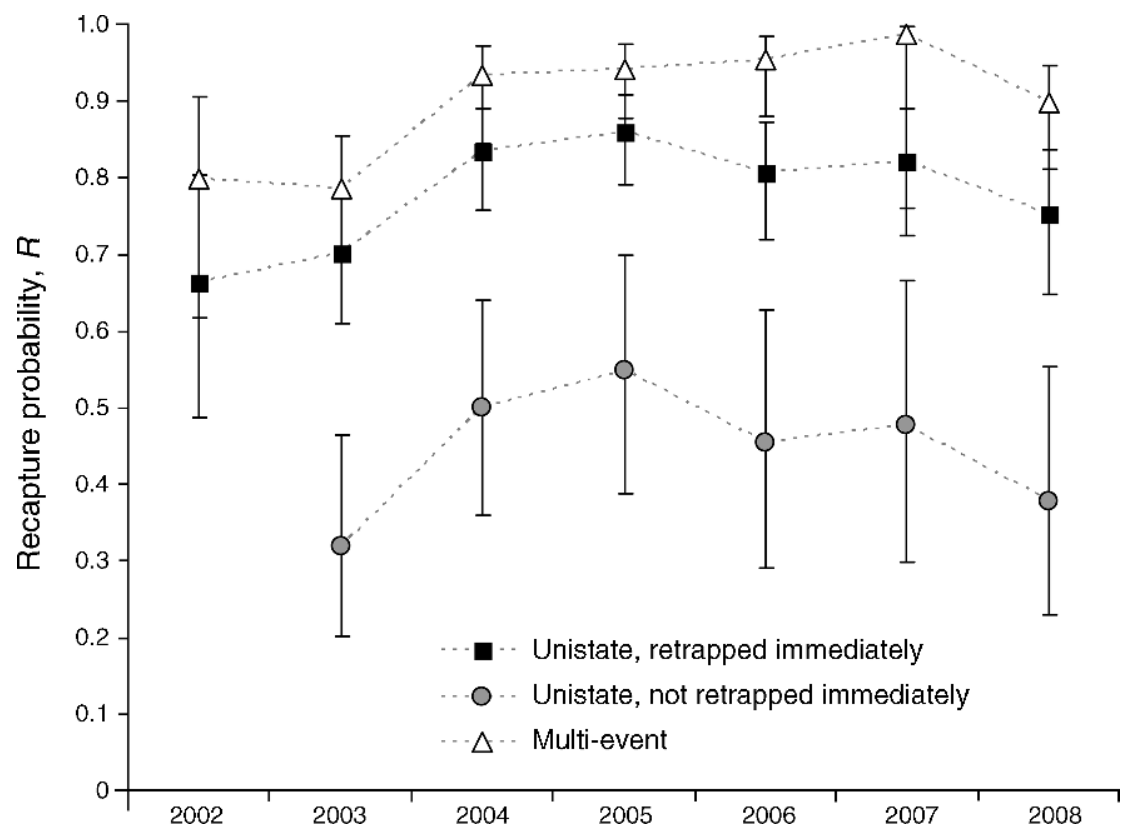

FIG. 4. Estimates of annual recapture probabilities of Cory's Shearwaters at Pantaleu Island, 2002-2008, obtained by unistate (Table 2, model 5) and multi-event (Table 3, model 5) capture-recapture modeling. 
TABLE 3. Modeling by multi-event capture-recapture models Cory's Shearwaters' probabilities of survival $(\Phi)$, between-state transitions $(\psi)$, recapture $(R)$, burrow inspection $(I)$, burrow occupancy $(K)$, and capture of the first $(F)$ and the second $(S)$ occupants of burrows where their previous occupants have not been recaptured at Pantaleu Island.

\begin{tabular}{|c|c|c|c|c|c|c|c|c|c|c|c|c|c|}
\hline \multirow{2}{*}{$\begin{array}{c}\text { Model } \\
\text { no. }\end{array}$} & \multicolumn{2}{|c|}{$\Phi$} & \multirow[b]{2}{*}{$\psi$} & \multirow[b]{2}{*}{$R$} & \multirow[b]{2}{*}{$I$} & \multirow[b]{2}{*}{$K$} & \multirow[b]{2}{*}{$F$} & \multirow[b]{2}{*}{$S$} & \multirow[b]{2}{*}{$\mathrm{np}$} & \multirow[b]{2}{*}{ Rdev } & \multirow[b]{2}{*}{$\mathrm{QAIC}_{\mathrm{c}}$} & \multirow[b]{2}{*}{$\Delta_{i}$} & \multirow[b]{2}{*}{$w_{i}$} \\
\hline & $\mathrm{nm}$ & res & & & & & & & & & & & \\
\hline 5 & . & . & $\mathrm{H}_{2}$ & $t$ & . & . & $t$ & $t$ & 29 & 6530.83 & 4896.46 & 0.00 & 0.78 \\
\hline 3 & . & . & $H_{1}$ & $t$ & . & . & $t$ & $t$ & 31 & 6528.76 & 4899.04 & 2.58 & 0.21 \\
\hline 2 & . & . & $H_{1}$ & $t$ & . & $t$ & $t$ & $t$ & 37 & 6521.57 & 4906.10 & 9.64 & 0.01 \\
\hline 4 & . & . & $H_{1}$ & . & . & . & . & . & 13 & 6613.58 & 4925.11 & 28.65 & 0.00 \\
\hline 6 & . & . & $\mathrm{H}_{3}$ & $t$ & . & . & $t$ & $t$ & 27 & 6680.68 & 5003.35 & 106.89 & 0.00 \\
\hline 1 & . & . & $H_{1}$ & $t$ & $t$ & $t$ & $t$ & $t$ & 43 & 6914.77 & 5209.81 & 313.35 & 0.00 \\
\hline
\end{tabular}

Notes: Abbreviations are: nm, newly marked birds; res, resident birds; np, number of estimable parameters; Rdev, relative deviance; $\mathrm{QAIC}_{\mathrm{c}}$, Akaike information criterion corrected for small sample size and overdispersion; $\Delta_{i}$, the QAIC $_{\mathrm{c}}$ difference between the current model and the one with the lowest $\mathrm{QAIC}_{\mathrm{c}}$ value; $w_{i}$, Akaike's weight. Model notation: $H_{1}$, transitions are constant in time but dependent on departure state; $\mathrm{H}_{2}$, transitions are constant in time with restricted dependence on departure state (states AP and AN [birds alive and breeding in the previous year's burrow or in a new burrow, respectively] are equivalent, but state AS [birds alive but in sabbatical; not breeding] is not); $H_{3}$, transitions are constant in time and independent of departure state; $t$, the time effect; ".", constant (i.e., no effects considered). The model with the highest $w_{i}$ is in boldface.

the other parameters of interest. All of the parameters in our models were estimable. The estimates of survival probabilities were very similar to those obtained by the classical unistate approach. Nevertheless, estimates of recapture probabilities obtained by the multi-event approach were higher because the unistate approach cannot separate the "true" recapture probability from temporary emigration. The estimate of sabbatical probability (0.15) in Cory's Shearwaters at Pantaleu Island (95\% CI: 0.11-0.20; Table 3, model 5) was similar to the estimate of the proportion of sabbatical years among possible breeding years obtained by Mougin et al. (1997) at Selvagem Island (between 9.9\% and 16.4\%), where all burrows were accessible and recapture probability of breeding birds was 1 .

\section{New biological insights}

Life-history theory predicts that reproduction is determined by an individual's decision related to its future chances to reproduce and/or survive (Stearns 1992). Intermittent breeding entails costs in terms of breeding seasons without reproductive output, but may be a strategy to enhance future breeding probabilities (Le Bohec et al. 2007). An interesting result of our

TABLE 4. Probabilities of sabbatical and burrow dispersal of Cory's Shearwater at Pantaleu Island obtained by model averaging (models 2, 3, 5; Table 3).

\begin{tabular}{lc}
\hline \hline \multicolumn{1}{c}{ Between-state transitions } & Estimate $(95 \% \mathrm{CI})$ \\
\hline $\begin{array}{l}\text { From AP to AN, change of burrow } \\
\text { From AN to AN, second change of }\end{array}$ & $0.04(0.03-0.06)$ \\
$\quad$ burrow & $0.04(0.03-0.08)$ \\
$\begin{array}{l}\text { From AS to AN, change of burrow after } \\
\quad \text { sabbatical }\end{array}$ & $0.20(0.11-0.32)$ \\
$\begin{array}{l}\text { From AP to AS, sabbatical } \\
\text { From AN to AS, sabbatical after change }\end{array}$ & $0.14(0.11-0.19)$ \\
$\quad$ of burrow & $0.16(0.11-0.24)$ \\
From AS to AS, second sabbatical & $0.63(0.45-0.78)$ \\
\hline
\end{tabular}

Note: In states AP and AN, birds are alive and breeding in the previous year's burrow or in a new burrow, respectively; in state AS, birds alive but in sabbatical, i.e., not breeding. analysis is that birds that have skipped reproduction were more prone to skip a second breeding attempt than were birds that bred. This is in discordance with the prudent-parent hypothesis, which predicts that nonbreeders would be expected to have a higher future breeding probability at the next occasion than breeders (Drent and Daan 1980, Le Bohec et al. 2007). Similar results, however, have been found by Barbraud and Weimerskirch (2005) for the Blue Petrel (Halobaena caerulea), Cam et al. (1998) for the Black-legged Kittiwake (Rissa tridactyla), Jiguet and Jouventin (1999) for the King Penguin (Aptenofytes patagonicus), and Tavecchia et al. (2005) for the Soay sheep (Ovis aries). All of these results suggest that intermittent breeding is a characteristic of individuals with a reduced ability to acquire a mate and breeding site, and to raise offspring, i.e., individuals with a lower intrinsic quality (Calladine and Harris 1997, Bradley et al. 2000). Moreover, we also found that the probability of nest site reoccupation was lower after absence than before, a result previously documented for the kittiwake (Danchin and Cam 2002). One possible explanation for the skipping behavior is that adult breeders might use a period of "sabbatical" to prepare themselves for a breeding career at a new higher quality site (Danchin et al. 1998). On the other hand, other birds might usurp the territory when it was not adequately defended, due to the absence of the previous owners, or when it is defended by a single owner as a consequence of divorce or death of the mate (Bruinzeel 2007). Contrarily to the results obtained by Danchin and Cam (2002) for the kittiwake, we did not observe substantial differences in future breeding probabilities between burrow-faithful birds and those that settled in a new nest. Estimates of the probabilities of sabbatical and change of burrow of birds that previously had changed their breeding site were slightly higher than for burrow-faithful breeders (Table 3, model 3; $w=0.21$ ), but confidence intervals overlapped greatly (Table 4). This suggests that burrow dispersal among birds that did not skip reproduction is 
not related to individual quality, and probably responds to disturbance or interannual changes in habitat features (Igual et al. 2007).

\section{Future perspectives}

Monitoring the "unobservable" proportion of nonbreeding individuals in a population is difficult, and this quantity usually has been neglected in population or evolutionary studies, despite its high impact on population dynamics (Kendall et al. 1997, Jenouvrier et al. 2005). The multi-event model presented here allows the combination of individual- and breeding-site-based information to simultaneously estimate breeding dispersal, survival, and the probabilities of skipping one or more reproductive event. Several biological, ecological, and evolutionary hypotheses concerning reproductive trade-offs can be tested simultaneously using this multievent approach, and robust estimates of demographic parameters can be obtained. In our example with Cory's Shearwater, we used such a method to study the influence of burrow fidelity and intermittent breeding on future changes of burrow and the probability of breeding. The flexibility of multi-event models permits one to test the potential influence of external covariates such as climatic conditions, monitoring effort, or predator pressure on the parameters of interest (Barbraud and Weimerskirch 2005, Jenouvrier et al. 2005, Le Bohec et al. 2007). We illustrated the use of a multi-event model in the study of temporal emigration in the Cory's Shearwater, but the extension of this approach to other biological systems is straightforward, as long as individual life histories can be coupled with data on breeding site or territory. For example, the model can be applied easily to species breeding in artificial nests or in sites that can be identified and monitored, i.e., territorial species. This includes birds, mammals, and reptiles. Furthermore, the merging of individual information with habitat characteristics can lead to more precise estimates of between-states transitions in spatially structured, as well as epidemiological, models. The flexibility of the model would allow the incorporation of time-invariant individual variables (e.g., sex or body condition at marking), and can be combined with a robust design (Kendall et al. 2009). Finally, additional states can be added to reflect individual breeding success as a measure of the effort invested in reproduction or as a proxy of individual quality to study reproductive trade-offs (Sanz-Aguilar et al. 2008).

\section{AcKNowledgments}

We are very grateful to Remi Choquet for his invaluable help with the software, to William L. Kendall, Michael Schaub, and two anonymous referees for their useful comments and suggestions, and to the personal of the Natural Park of Dragonera Island, especially to Martí Mayol. Ana SanzAguilar was supported by a postgraduate grant (ref. AP20041128) and Meritxell Genovart by an I3P postdoctoral fellowship, both from the Spanish Ministry of Science, which also funded the monitoring scheme through several grants (refs. BOS2003-01960, CGL2006-04325/BOS and SAB-2006-0014).

\section{Literature Cited}

Bailey, L. L., T. R. Simons, and K. H. Pollock. 2004. Spatial and temporal variation in detection probability of plethodon salamanders using the robust capture-recapture design. Journal of Wildlife Management 68:14-24.

Barbraud, C., and H. Weimerskirch. 2005. Environmental conditions and breeding experience affect costs of reproduction in Blue Petrels. Ecology 86:682-692.

Blums, P., J. D. Nichols, J. E. Hines, and A. Mednis. 2002. Sources of variation in survival and breeding site fidelity in three species of European ducks. Journal of Animal Ecology 71:438-450.

Bradley, J. S., R. D. Wooller, and I. J. Skira. 2000. Intermittent breeding in the short-tailed shearwater Puffinus tenuirostris. Journal of Animal Ecology 69:639-650.

Bried, J., and P. Jouventin. 1999. Influence of breeding success on fidelity in long-lived birds: an experimental study. Journal of Avian Biology 30:392-398.

Bried, J., D. Pontier, and P. Jouventin. 2003. Mate fidelity in monogamous birds: a re-examination of the Procellariiformes. Animal Behaviour 65:235-246.

Bruinzeel, L. W. 2007. Intermittent breeding as a cost of site fidelity. Behavioral Ecology and Sociobiology 61:551-556.

Burnham, K. P., and D. R. Anderson. 2002. Model selection and multimodel inference a practical information-theoretic approach. Springer, New York, New York, USA.

Calladine, J., and M. P. Harris. 1997. Intermittent breeding in the Herring Gull Larus argentatus and the Lesser Blackbacked Gull Larus fuscus. Ibis 139:259-263.

Cam, E., J. E. Hines, J. Y. Monnat, J. D. Nichols, and E. Danchin. 1998. Are adult nonbreeders prudent parents? The kittiwake model. Ecology 79:2917-2930.

Catry, P., R. A. Phillips, K. C. Hamer, N. Ratcliffe, and R. W. Furness. 1998. The incidence of nonbreeding by adult Great Skuas and Parasitic Jaegers from Foula, Shetland. Condor 100:448-455.

Cézilly, F., F. Dubois, and M. Pagel. 2000. Is mate fidelity related to site fidelity? A comparative analysis in Ciconiiforms. Animal Behavior 59:1143-1152.

Chastel, O., H. Weimerskirch, and P. Jouventin. 1995. Body condition and seabird reproductive performance: a study of three petrel species. Ecology 76:2240-2246.

Choquet, R., J.-D. Lebreton, O. Gimenez, A. M. Reboulet, and R. Pradel. 2009a. U-CARE: Utilities for performing goodness of fit tests and manipulating CApture-REcapture data. Ecography 32:1071-1074.

Choquet, R., A. M. Reboulet, R. Pradel, O. Gimenez, and J.-D. Lebreton. 2004. M-SURGE: new software specifically designed for multistate capture-recapture models. Animal Biodiversity and Conservation 27:207-221.

Choquet, R., L. Rouan, and R. Pradel. 2009b. Program ESURGE: a software application for fitting multievent models. Pages 845-865 in D. L. Thomson, E. G. Cooch, and M. J. Conroy, editors. Modeling demographic processes in marked populations. Environmental and ecological statistics. Volume 3. Springer, York, UK.

Coulson, T., G. M. Mace, E. Hudson, and H. P. Possingham. 2001. The use and abuse of population viability analysis. Trends in Ecology and Evolution 16:219-221.

Crespin, L., M. P. Harris, J.-D. Lebreton, M. Frederiksen, and S. Wanless. 2006. Recruitment to a seabird population depends on environmental factors and on population size. Journal of Animal Ecology 75:228-238.

Danchin, E., T. Boulinier, and M. Massot. 1998. Conspecific reproductive success and breeding habitat selection: implications for the study of coloniality. Ecology 79:2415-2428. 
Danchin, E., and E. Cam. 2002. Can non-breeding be a cost of breeding dispersal? Behavioral Ecology and Sociobiology 51: 153-163.

Drent, R. H., and S. Daan. 1980. The prudent parent: energetic adjustments in avian breeding. Ardea 68:225-252.

Fujiwara, M., and H. Caswell. 2002. A general approach to temporary emigration in mark-recapture analysis. Ecology 83:3266-3275.

Genovart, M. 2001. Seguiment de la colònia de cria de virot (Calonectris diomedea) a l'illot d'Es Pantaleu. Anuari Ornitològic de les Balears 16:23-27.

Harris, M. P., and S. Wanless. 1995. Survival and non-breeding of adult Common Guillemots Uria aalge. Ibis 137:192-197.

Igual, J. M., M. G. Forero, T. Gomez, and D. Oro. 2007. Can an introduced predator trigger an evolutionary trap in a colonial seabird? Biological Conservation 137:189-196.

Igual, J. M., G. Tavecchia, S. Jenouvrier, M. G. Forero, and D. Oro. 2009. Buying years to extinction: is compensatory mitigation for marine bycatch a sufficient conservation measure for long-lived seabirds? PloS ONE 4(3):e4826. [doi: 10.1371/journal.pone.0004826]

Jenouvrier, S., C. Barbraud, B. Cazelles, and H. Weimerskirch. 2005. Modelling population dynamics of seabirds: importance of the effects of climate fluctuations on breeding proportions. Oikos 108:511-522.

Jenouvrier, S., G. Tavecchia, J. C. Thibault, R. Choquet, and V. Bretagnolle. 2008. Recruitment processes in long-lived species with delayed maturity: estimating key demographic parameters. Oikos 117:620-628.

Jiguet, F., and P. Jouventin. 1999. Individual breeding decisions and long-term reproductive strategy in the King Penguin Aptenodytes patagonicus. Ibis 141:428-433.

Kendall, W. L., and R. Biorkland. 2001. Using open robust design to estimate temporary emigration from capturerecapture data. Biometrics 57:1113-1122.

Kendall, W. L., S. J. Converse, P. F. Doherty, M. B. Naughton, A. Anders, J. E. Hines, and E. Flint. 2009. Sampling design considerations for demographic studies: a case of colonial seabirds. Ecological Applications 19:55-68.

Kendall, W. L., and J. D. Nichols. 1995. On the use of secondary capture-recapture samples to estimate temporary emigration and breeding proportions. Journal of Applied Statistics 22:751-762.

Kendall, W. L., and J. D. Nichols. 2002. Estimating statetransition probabilities for unobservable states using capture-recapture/resighting data. Ecology 83:3276-3284.

Kendall, W. L., J. D. Nichols, and J. E. Hines. 1997. Estimating temporary emigration using capture-recapture data with Pollock's robust design. Ecology 78:563-578.

Le Bohec, C. L., M. Gauthier-Clerc, D. Gremillet, R. Pradel, A. Bechet, J. P. Gender, and Y. L. Maho. 2007. Population dynamics in a long-lived seabird: I. Impact of breeding activity on survival and breeding probability in unbanded king penguins. Journal of Animal Ecology 76:1149-1160.

Lebreton, J.-D., K. P. Burnham, and J. Clobert. and D. R. Anderson.1992. Modeling survival and testing biological hypotheses using marked animals: a unified approach with case studies. Ecological Monographs 62:67-118.

Mougin, J. L., C. Jouanin, and F. Roux. 1997. Intermittent breeding in Cory's shearwater Calonectris diomedea of Selvagem Grande, North Atlantic. Ibis 139:40-44.

Mougin, J. L., C. Jouanin, and F. Roux. 2000. Mate fidelity in Cory's Shearwater Calonectris diomedea on Selvagem Grande. Ibis 142:421-427.

Newton, I. 1989. Lifetime reproduction in birds. Academic Press, London, UK.

Oro, D., J. S. Aguilar, J. M. Igual, and M. Louzao. 2004. Modelling demography and extinction risk in the endangered Balearic shearwater. Biological Conservation 116:93-102.

Pradel, R. 1993. Flexibility in survival analysis from recapture data: handling trap-dependence. Pages 29-37 in J.-D. Lebreton and P. M. North, editors. Marked individuals in the study of bird population. Birkhauser Verlag, Basel, Switzerland.

Pradel, R. 2005. Multievent: an extension of multistate capturerecapture models to uncertain states. Biometrics 61:442-447.

Pradel, R., J. E. Hines, J.-D. Lebreton, and J. D. Nichols. 1997. Capture-recapture survival models taking account of transients. Biometrics 53:60-72.

Sanz-Aguilar, A., G. Tavecchia, R. Pradel, E. Mínguez, and D. Oro. 2008. The cost of reproduction and experiencedependent vital rates in a small petrel. Ecology 89:3195-3203.

Schaub, M., O. Gimenez, B. Schmidt, and R. Pradel. 2004. Estimating survival and temporary emigration in the multistate capture-recapture framework. Ecology 85:21072113.

Schwarz, C. J., and W. T. Stobo. 1997. Estimating temporary migration using the robust design. Biometrics 53:178-194.

Stearns, S. C. 1992. The evolution of life histories. Oxford University Press, Oxford, UK.

Tavecchia, G., T. Coulson, B. J. T. Morgan, J. M. Pemberton, J. C. Pilkington, F. M. D. Gulland, and T. H. Clutton-Brock. 2005. Predictors of reproductive cost in female Soay sheep. Journal of Animal Ecology 74:201-213.

Thibault, J. C. 1994. Nest-site tenacity and mate fidelity in relation to breeding success in Cory's shearwater Calonectris diomedea. Bird Study 41:25-28.

Viallefont, A., F. Cooke, and J.-D. Lebreton. 1995. Age-specific costs of first-time breeding. Auk 112:67-76.

Warham, J. 1990. The petrels; their ecology and breeding systems. Academic Press, London, UK.

Yoccoz, N. G., J. D. Nichols, and T. Boulinier. 2001. Monitoring of biological diversity in space and time. Trends in Ecology and Evolution 16:446-453.

\section{APPENDIX}

Details concerning the multi-event capture-recapture modeling approach and its implementation in program E-SURGE (Ecological Archives A021-030-A1). 